\title{
URBAN MULTISENSORY LABORATORY, AN APPROACH TO MODEL URBAN SPACE HUMAN PERCEPTION
}

\author{
T. González, D. Sol, J. Saenz, D. Clavijo, H. García \\ Tecnológico de Monterrey en Puebla, México - tgonzalezc@itesm.mx, dsol@itesm.mx, jasaenz@itesm.mx, dclavijo@itesm.mx, \\ a01129778@itesm.mx
}

KEY WORDS: Urban Space Laboratory, Emotional Response, Qualitative analysis, Urban Knowledge, Design Thinking, Data analysis, Public space understanding

\begin{abstract}
:
An urban sensory lab (USL or LUS an acronym in Spanish) is a new and avant-garde approach for studying and analyzing a city. The construction of this approach allows the development of new methodologies to identify the emotional response of public space users. The laboratory combines qualitative analysis proposed by urbanists and quantitative measures managed by data analysis applications. USL is a new approach to go beyond the borders of urban knowledge. The design thinking strategy allows us to implement methods to understand the results provided by our technique. In this first approach, the interpretation is made by hand. However, our goal is to combine design thinking and machine learning in order to analyze the qualitative and quantitative data automatically. Now, the results are being used by students from the Urbanism and Architecture courses in order to get a better understanding of public spaces in Puebla, Mexico and its interaction with people.
\end{abstract}

\section{INTRODUCTION}

Our concept of cities has been changing for a long time. From static structures to smart environments, we have brought to life these complex organisms as an extension of ourselves. Can a city be empathic with its users? How our surroundings affect our living standards? If a city can be empathic, how can we design more empathic cities? This and other questions can be solved nowadays thanks to the Internet of Things (IoT). This paper intends to measure our perception of urban spaces and give us a more robust definition of the attributes that define the invisible connection between us and the sleeping giant in which we live.

\section{STATE OF THE ART}

The study of city perception started in the early 40's; moreover, the theory was based on visual perception and only psychologists were interested in the matter. Later, a theoretical socialist called Guy Debord proposed a new way to share urban spaces by doing psycho-geography; an unconventional kind of tour. These tours were short and the tourists would give psychological descriptions. The purpose of this was to find conventional patterns by using the "derives" technique (Debord, 1958).

Kevin Andrew Lynch was the first urbanist to connect Architecture with human perception in 1960. He thought that people should be connected to the environment; "we are not only observers, we are part of the scene, all the senses work together and the image is a combination of the perception of all senses" (Lynch, 1960). Any image from the real world has three components: identity, structure, and meaning (Gibson, 1979). James Jerome Gibson an American psychologist, states that all the information that a person perceives from the environment is wrapped by a visual and environmental pattern (Gibson, 1979).
As mentioned before, at the beginning, everything was focused on visual perception. As the study in the matter continued, there were changes; for example, Alexander Cowan and Jill Stewart, described in their book: "City and senses: urban culture from 1500 " the city life as a sensorial dimension that involved all of our senses. They recognized that the visual sense is very important but the others are a fundamental component in the construction of the whole picture (Cowan \& Stewart, 2007). The premise "the perception is multi-sensorial", is used by several authors working on the subject. They think that perception is a conscious action; "the base is the reject that perception is an identical phenomenon for different people, perception is produced by processes" (Marcel, 1983).

After the 80 's, the experts started to work on the urban model supported by the idea that perception can be done by conscious or not conscious processes. Space design was based on user experience but not only during the process of design but also during the regular use. This approach required systems and technology to support observation and evaluation in real time (Westerink et al 2008).

Cognitive maps proposed by Lynch are widely used to represent the conscious human perception. This tool allows representing a subjective perception in small urban sectors (Downs and Stea, 1973), (Downs et al, 1978). Environmental perception includes a set of attitudes, motivations, and values to influence in different social sectors, this influence can determine the behavior of people inside an urban space (Rapoport, 1978). The qualitative and quantitative analysis consider psychological, cognitive, emotional and behavioral perception altogether supported by senses (Westerink et al 2008).

In summary, our aim is to contribute to the empirical study of urbanism measuring the emotional response people that have in public places. Combining qualitative analysis and quantitative data like temperature, noise, and light, we plan to have an approximation of what perception might be. We think that 
changes in urban space can change the users' emotional experience.

\section{METHODOLOGY}

Our method to describe space human perception is proposed by urban experts under a set of variables. The variables include not only eyesight, but they also try to consider other aspects of human perception. The method is a first approach for an urban sensory lab (USL) to describe an urban space and it includes quantitative and qualitative aspects. Quantitative variables are measured by temperature, light, humidity and noise sensors, as well as coordinates location (latitude and longitude) and time. The qualitative information is obtained by a specific interview developed by a group of urban experts. The set of qualitative data is evaluated by the Urban and Architecture experts to describe user's perception. These variables are classified in: expectations, barriers, needs and experiences, and correlated to four ways of expression: thought, say, feeling and action. At the moment, qualitative variables are analyzed manually. It means that an expert has to read the information and formulate a proper conclusion. This conclusion makes powerful insights in order to improve urban facilities and, consequently, user's experience. The data variables obtained may lead to a full automate analysis, but this automation will be included in further implementations.

Our methodology is based in four different phases:

1. Development of the general strategy.

2. Quantitative and qualitative analysis.

3. Web integration.

4. Testing.

\subsection{Development of the general strategy}

The first phase focuses on creating the best strategy to study public spaces. Using the Six Sigma methodology, we reduced the number of variables of study into the eight most significant:

- Shadow

- Vegetation

- Noise

- Criminal activity

- Awkwardness

- Pollution

- Indoors structure

- Urban facilities

From the variables listed above, we noticed that, shadow and noise could be obtained by using light and noise sensors. In addition, we thought that temperature and humidity could add powerful information for vegetation, and pollution descriptors. The strategy was to combine qualitative and quantitative data. For gathering qualitative data, we created an interview for urban users. The strategy consisted on the following:

1. Selecting the urban area for study.

2. Sensor positioning.

3. Selecting specific type of users for making the interviews.

4. Gathering and structuring data.

5. Insights discovery.
6. Resulting conclusions.

7. Clustering conclusions into three main objectives: improve, develop or preserve.

It is important to notice that every process is done manually; there are students from Architecture who are in charge of positioning the sensors and making the interviews. Likewise, a specialist in the subject analyzes the data and proposes the insights and conclusions.

\subsection{Qualitative and quantitative analysis}

The qualitative analysis is based on an interview. This interview had to be structured in a way the interviewed was not influenced at all by the interviewer and also that could be easily repeated. Therefore, we use the design thinking technique to provide a solution to this problem. This methodology uses five different stages which are: empathize, define, ideate, prototype and test.

The purpose of the interview is to know the perception of a user for a specific urban area. Questions made are organized in five areas of study, and we ask the users to answer the questions by choosing one out of four different predefined images (called empathy cards) and to briefly explain their selection. Every interview is recorded or written depending on the user. Figure 1 shows some examples of urban spaces.
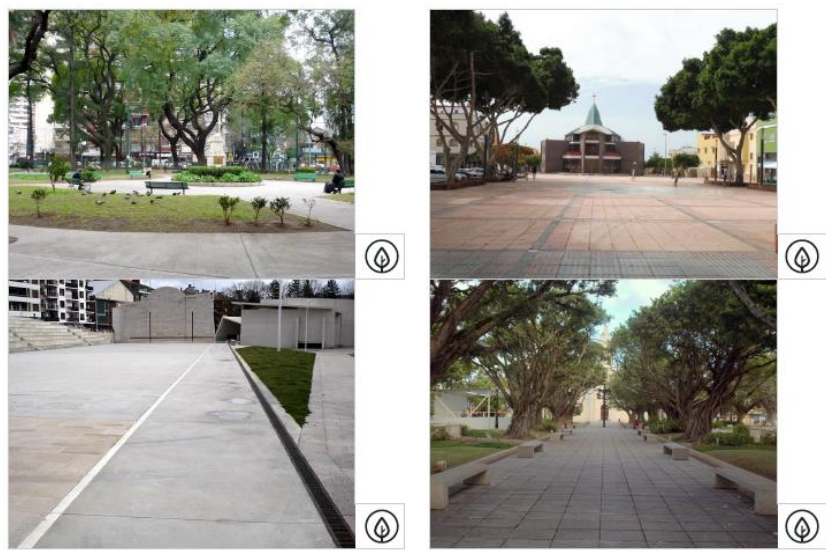

Fig. 1 Example of empathy cards.

After making the interviews, the information has to be processed before updating to the database. In order to make easier this interpretation, the interviewers need to follow the next path:

a. Write down every observation in short phrases and classify them into four different types: thought, speaking, feeling and action. E.g Lucía said she does not go out very often because the place is very dark (category: thought).

b. Crossover observations: after writing down the observations, these must be categorized in expectations, barriers, needs or experiences.

c. Obtaining the Insights: taking in consideration the matrix previously created, insights discovered must be formatted down as necessity (want) + trigger (why?) + contrast (but). E.g. I like playing with my friends on the street because it makes me feel free but it is dangerous. 
d. Crossover insights or conclusions: this step takes into account the measurements from the sensors and the obtained insights is made by an expert in the matter and must conclude if the urban space has to be improved, developed, or preserved.

The set of qualitative variables are evaluated by urban experts to describe the multi-sensorial aspects. At the moment, qualitative variables are analyzed by hand. This means that an expert needs to read the observations and formulate a conclusion about the urban space of study. The conclusion will present suggestions to improve the use of urban space. Some of the variables for the qualitative data can automate analysis, but this automation will be included in a future step for this project.

Quantitative analysis gives an objective view of the study site. It is intended, by sensing temperature, noise, luminosity and humidity to create a correlation between the user's perception and sensed data. To obtain this type of data, we study several types of technologies that could sense the environment in different ways. The device selected was the Bosch XDK110 Cross-Domain Development Kit. It is a wireless sensor device that is used for prototyping applications for the Internet of Things (BOSCH,2015). The sensor operating conditions are:

- Humidity range (BME280): $10 \quad \ldots$ 90\%rH (noncondensing)

- Temperature (BME280): $-20^{\circ} \mathrm{C} \ldots 60^{\circ} \mathrm{C}$

- Light sensor (MAX44009): 0.045 lux ... 188,000 lux; 22-bit

- Acoustic noise sensor (AKU340): $50 \mathrm{~Hz}-20 \mathrm{kHz}$, $38 \mathrm{~dB}+/-2 \mathrm{~dB}$ sensitivity

\subsection{Web integration}

The web application shows the integration and a web map presenting the urban area where the spaces are located and can be described in three main sections:

1. Web Graphical User Interface: User dashboard and data visualization, allows the users to view, browse and register the data collected by the mobile application and the sensor module.

2. Mobile Graphical User Interface: Its main purpose is to act as a link between the sensor module and the application web architecture. By means of this interface the user starts and uploads data into the web application.

3. Sensor Module: a general purpose module that describes all aspects of the physical configuration and low level language that allows the correct operation of the sensors with the database and consequently the integration of the elements in the upper layers.

Our actual architecture is described in the Figure 2. Data are collected by sensors and them are pushed to the database. At this moment, urbanists analyze these data by hand and they cross these data with information obtained by interviews. The experiment will allow us to construct an algorithm to classify urban spaces based on their attributes. Our architecture allows the project to run the studies at a very low cost by relying on the user mobile phone and the web browser interface in order to process and register data.
The location of the urban spaces is presented to the urbanist by the USL dashboard (Fig 3).

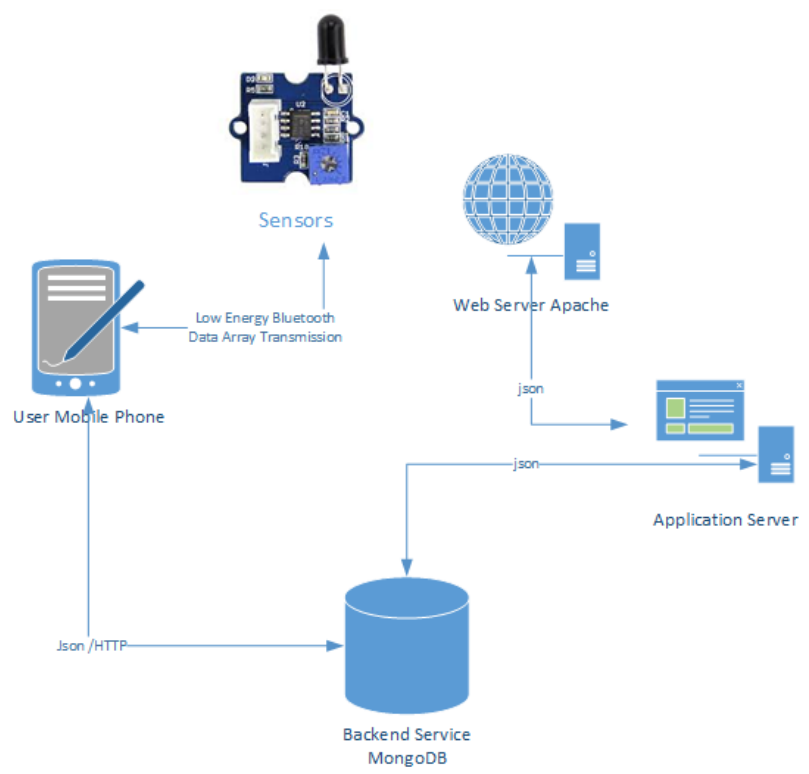

Fig. 2 Architecture

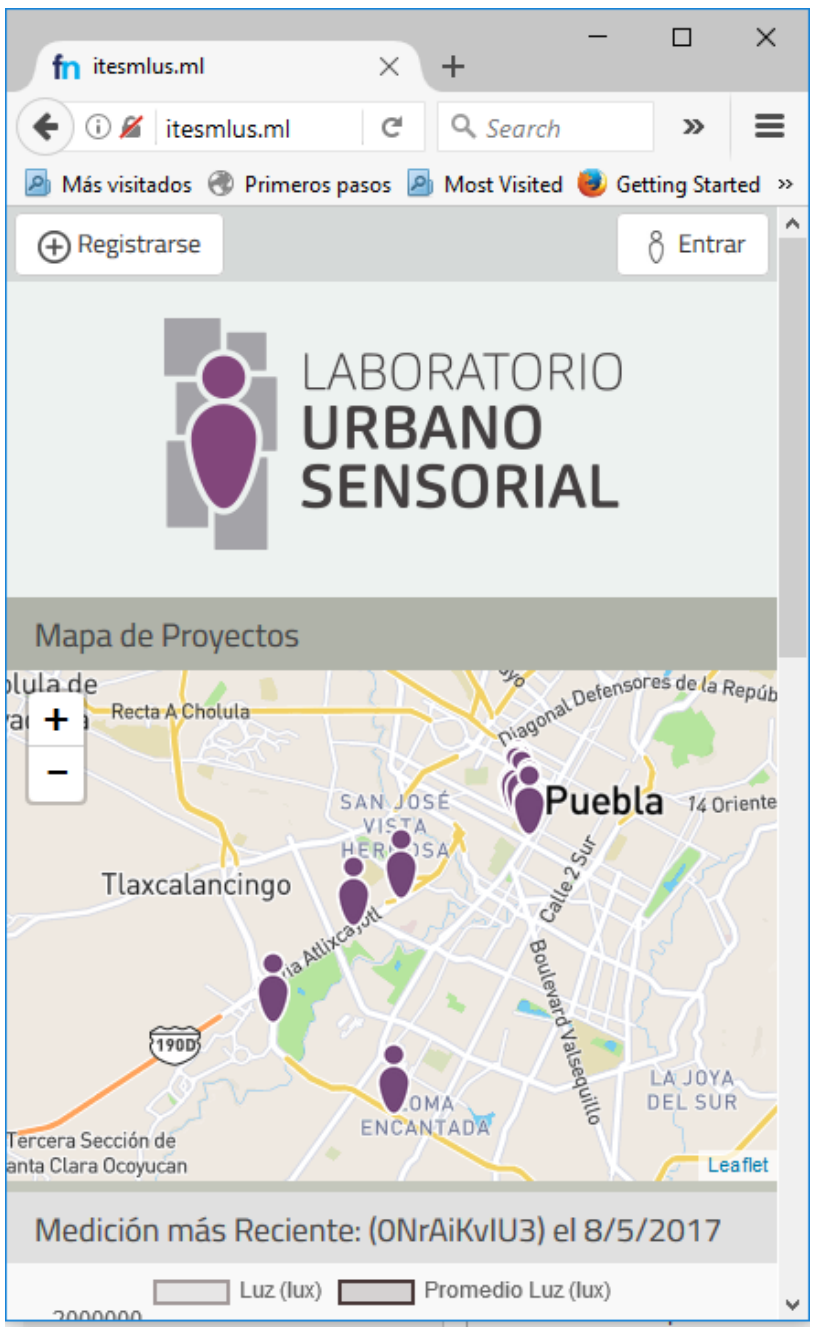

Fig. 3 USL Web Site: http://itesmlus.ml/ 
The web platform has been very useful to guide the manual implementation of this process. This style of architecture is well known in the web application context, but will be very important to automate the multi-sensorial data analysis and the implementation of new methods to describe urban spaces. It is important this description which helps to understand the USL framework.

\subsection{Testing}

The testing process has seven steps:

1. Definition of the project and variables identification

2. Sensor identification and location

3. User identification

4. Users empathy to get qualitative data

5. Addition of qualitative data on the USL web application

6. Quantitative and Qualitative data correlation

7. Evaluation

The first step is to identify the urban space of study. It is important to visit the place of study before making the interviews in order to detect best practices and type of users. It will be useful to take notes or make drawings in order to describe the site. It is important to classify users and strategical spaces specified by the interviewers on the areas of study. The analysis must be selective and the interviewers must know the methodology in order to find the expectations, barriers, needs and experiences of the users.

Once the qualitative variables are identified, the sensors need to be placed. The sensor location must be selected in order to get the representative context of the area of study. The sensors and a smart phone need to be configured to communicate by Bluetooth. Each measure has an id (identifier) which will be used to associate the qualitative and the quantitative data.

The third step is the identification of users. Design Thinking Method proposed the group IDEO (Dschool, 2009). Every urban space has its own properties. For this reason, Design Thinking (Design Thinking, 2017) propose different strategies to be used based on the project specification. It is possible to identify three types of users: extreme users, leader users and archetype users. Extreme users are the ones who almost never use the public space or use it very frequently (opposite poles). Leader users must have a wide perception of the space and they should provide general information regarding the point of view of different users, and finally, the archetype users are the ones that can be found more frequently, for instance, a park which can be attractive for young people.

In the fourth step, we continue the Design Thinking technique by using empathy cards, which are images and photos that show nice areas. A team composed by two people develop the interview, the first one does the interview and the second one takes notes about the words and the reaction of the people. This person can record the interview if the interviewed allows it. An important aspect is to never suppose answers. Every answer needs to be as objective as could be. In this step, the interviewer can get additional information by asking the user to design a cognitive map of the site. This tool allows us to get a more precise picture of the user's perception. Other techniques can be used to get deeper into users' point of view. For example; The Fly on the wall tool suggests staying in the site for a long period (about two hours) to note the people interactions and reactions.
On the other hand, a guided tour could be useful to the user to describe the site in a different order.

The fifth step is to input the data obtained into our web integration. After this step, the automation can begin. It is quite difficult to automate previous steps because the urbanist guides the conversation and she/he observes and analyses the user in order to get their feelings and thoughts. In the sixth step, the qualitative data is correlated to the quantitative data recorded by the sensors. i.e. position, temperature, movement, noise and humidity.

Finally, the data is analyzed by experts in the matter in order to get an overview evaluation of the site. The section 3.2 Qualitative and Quantitative analysis describe in detail this step.

Once the testing process is done, the obtained data can be visualized in a database table. This information aims to represent one single event (interview) per tuple. An example is listed in the Table 1 in order to have a more descriptive explanation of our results:

- Location: $19.021136,-98.245310$

- Date: $15 / 03 / 2017$

- $\quad$ Start Time: 10:07 hrs

- $\quad$ End Time: 10:45 hrs

- Noise representative value: $70 \mathrm{~dB}$

- Light representative value: 18089291.69 lux

- Temperature representative value: $33.546^{\circ} \mathrm{C}$

- Humidity representative value: $18.79 \%$

- Number of interview: 1

- Gender: M

- Age: 22

- Crossover observations:

\begin{tabular}{|l|l|l|l|l|}
\cline { 2 - 5 } \multicolumn{1}{c|}{} & Thought & Say & Feeling & Action \\
\hline Expectations & $\begin{array}{l}\text { Going by } \\
\text { the } \\
\text { bikeway } \\
\text { isn't that } \\
\text { bad. }\end{array}$ & $\begin{array}{l}\text { Sometimes } \\
\text { it's hard to } \\
\text { enter the } \\
\text { bikeway. }\end{array}$ & Impatience & Doubt \\
\hline Barriers & $\begin{array}{l}\text { Decrease } \\
\text { the slope } \\
\text { degree. }\end{array}$ & $\begin{array}{l}\text { Some } \\
\text { entries to } \\
\text { the } \\
\text { bikeway } \\
\text { are in bad } \\
\text { shape. }\end{array}$ & $\begin{array}{l}\text { Fear he could } \\
\text { result injured. }\end{array}$ & $\begin{array}{l}\text { Takes } \\
\text { another } \\
\text { entry } \\
\text { which is } \\
\text { in better } \\
\text { shape. }\end{array}$ \\
\hline Needs & $\begin{array}{l}\text { Lack of } \\
\text { vegetation } \\
\text { makes } \\
\text { unbearable } \\
\text { the } \\
\text { bikeway } \\
\text { use. }\end{array}$ & $\begin{array}{l}\text { There } \\
\text { should be } \\
\text { more } \\
\text { places to } \\
\text { cover from } \\
\text { sunlight. }\end{array}$ & $\begin{array}{l}\text { Uncomfortable } \\
\text { Covers } \\
\text { his head } \\
\text { with his } \\
\text { hand. }\end{array}$ \\
\hline Experiences & $\begin{array}{l}\text { The } \\
\text { bikeway is } \\
\text { safer than } \\
\text { the } \\
\text { sidewalk. }\end{array}$ & $\begin{array}{l}\text { It is safer } \\
\text { to walk on } \\
\text { bikeway } \\
\text { during the } \\
\text { morning. }\end{array}$ & Unsafety & $\begin{array}{l}\text { Cleans his } \\
\text { forehead } \\
\text { sweat. }\end{array}$ \\
\hline
\end{tabular}

Table 1. Example of qualitative variables data base

- Insights: 
- The lack of benches makes exhausting to walk to my job.

○ I want to walk covered from the sunlight because it is a long way to my job. Not enough vegetation.

- I want to walk back to my home but it is a long way and its very dark.

○ The bikeway exit to my job is in bad shape which makes me feel fear.

- Crossover insights (Table 2):

\begin{tabular}{|c|c|c|c|}
\hline & Improve & Develop & Preserve \\
\hline Cleaning & & & $\mathrm{x}$ \\
\hline Noise & & & $\mathrm{x}$ \\
\hline Security & & $\mathrm{x}$ & \\
\hline Furniture & $\mathrm{x}$ & & \\
\hline vegetation & $\mathrm{x}$ & & \\
\hline
\end{tabular}

Table 2. Example of crossover insights

\section{RESULTS}

We have developed eleven experiments in Puebla, Mexico that are available on the web site. A first view of the results is presented in the Fig. 4.

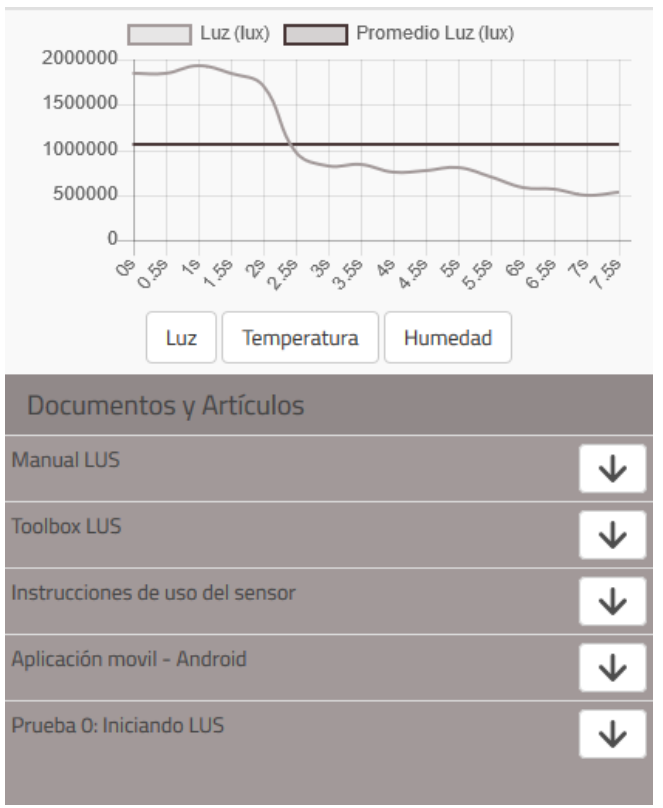

Fig. 4 Presentation of results

The first two experiments were done in October 2016. The goal was to have a trial version to review the development of the platform and methodology. The spaces selected are close to the university and have a high population density during the rush hours. The places were:

- Baroque museum

- University cultural complex
Afterwards, from January to May 2017, another three experiments were developed for the bikeway of Via Atlixcayotl and Periférico. The results obtained respond to the matrix presented in the Table 3.

\begin{tabular}{|c|c|c|c|c|}
\hline \multicolumn{5}{|c|}{ Conclusions } \\
\hline Category & Recommendations & Improve & Develop & Preserve \\
\hline Cleaning & & & & \\
\hline Furniture & $\begin{array}{l}\text { The distance is very } \\
\text { long and there are not } \\
\text { many places to sit with } \\
\text { shade. }\end{array}$ & $\mathrm{x}$ & & \\
\hline \multicolumn{5}{|l|}{ Noise } \\
\hline \multirow{3}{*}{ Security } & $\begin{array}{lr}\text { Pedestrian } & \text { bridges } \\
\text { create a } & \text { sense of } \\
\text { insecurity, } & \text { other } \\
\text { alternatives } & \text { should be } \\
\text { considered. } & \end{array}$ & $\mathrm{x}$ & & \\
\hline & $\begin{array}{l}\text { Walking and running } \\
\text { spaces must have } \\
\text { sufficient lighting to } \\
\text { give the feeling of } \\
\text { safety. }\end{array}$ & $\mathrm{x}$ & & \\
\hline & $\begin{array}{l}\text { Spaces that detonate } \\
\text { the presence of people } \\
\text { (trade) give greater } \\
\text { perceived security. }\end{array}$ & $\mathrm{x}$ & & \\
\hline Vegetation & $\begin{array}{l}\text { It takes vegetation to } \\
\text { generate shade, but } \\
\text { you have to be careful } \\
\text { not to cover the visual. }\end{array}$ & $\mathrm{x}$ & & \\
\hline
\end{tabular}

Table 3. Conclusions on crossover insights

As can be observed, the most frequent variable is security. On the other hand, the cleaning and noise variables does not seem to be as important as we thought. However, shadow became a point of interest throughout the interviews.

In addition to, the neighborhoods Los Volcanes and Barrio de Santiago were evaluated. Six interviews were carried out for this area. Results of the evaluation are presented in the Table 4.

\begin{tabular}{|l|l|l|l|l|}
\hline \multicolumn{5}{|c|}{ Conclusions } \\
\hline Category & Recommendations & Improve & Develop & Preserve \\
\hline Cleaning & $\begin{array}{l}\text { I want urban furniture } \\
\text { made with vernacular } \\
\text { materials because it is } \\
\text { important to save and } \\
\text { preserve the nature of } \\
\text { the site but obsolete } \\
\text { designs are currently } \\
\text { used. }\end{array}$ & $\begin{array}{l}\text { I want a space in good } \\
\text { conditions because it } \\
\text { has better visual } \\
\text { appearance, but the } \\
\text { users do not take care } \\
\text { of the furniture. }\end{array}$ & & \\
\hline
\end{tabular}




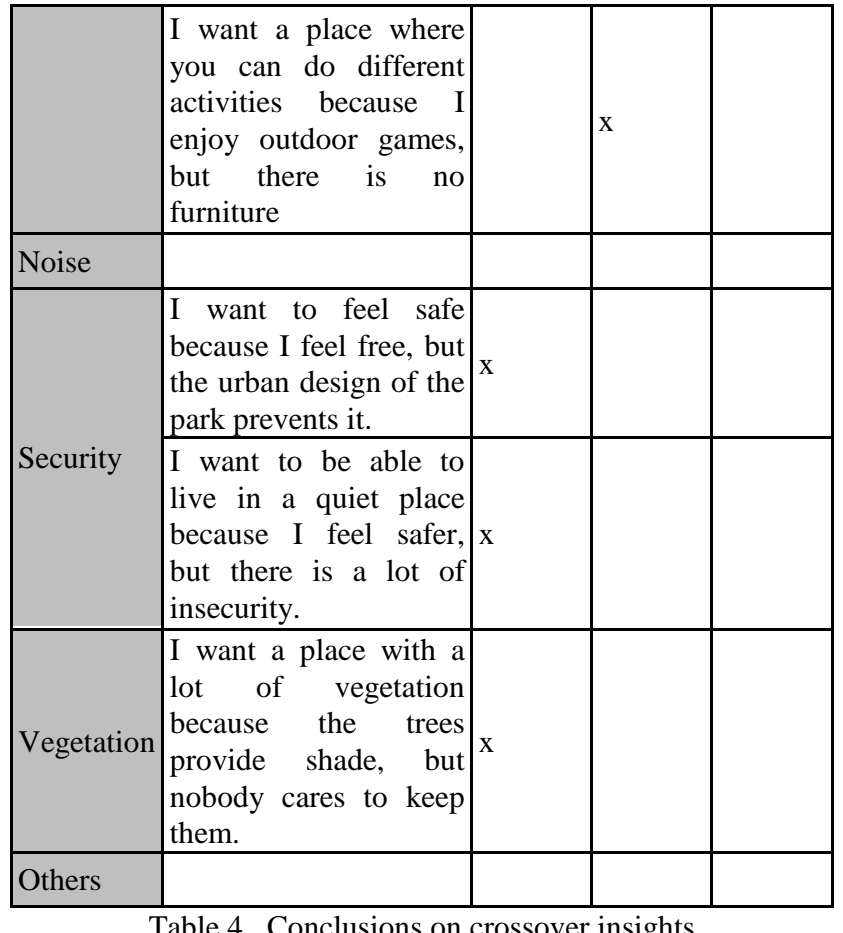

As can be observed, the most frequent variable is mobility followed by security. Also, vegetation is commonly linked to the shadow of the place. In this experiment, we have similar results to the bikeway experiment, the cleaning and noise variables were not mentioned.

\section{FURTHER WORK}

A first working line will consist on developing a machine learning framework where the crossover insights will automatically be obtained. By using data mining techniques and artificial intelligence algorithms (AI) it is our intention to find hidden patterns that could describe the social environment we live in. This process simplification will help to have more precise and objective conclusions, as well as a trustworthy base for urban development.

In addition to this, it is important to improve our sensor programming in order to increase the battery efficiency and data sampling. It is intended to remove the Bluetooth communication in order to simplify the usage of the device. In near future data will be stored inside the device's memory. Furthermore, the quantitative data needs to include more complex ways of processing in order to have a more accurate environment description.

On the other hand, it is our plan to extend our approach to spaces dedicated to sale and construction of handicrafts. Industrial design area collaborates with Mexican handicrafts in objects development, textile and painting to generate new products for young and different people. In this case, urban space plays an important role to give an atmosphere and an environment to give peace and adequate space for this kind of activities. Artisans can work inside a space which promote the senses. At the same time, their families can work and sell their products. At this moment, only the research is focused on the products and the business model, but we are interested to work on the urban space perception to develop and strength this type of activities. The tradition and the culture can be promoted in urban areas where locals and tourists can approach handicrafts products (Usigli, 2016).

Furthermore, to face the urban challenges of the global urban explosion, the countries that make up the UN decided to organize the conference on "housing and sustainable urban development, Habitat", which is held every 20 years. The first was in Vancouver, Canada in 1976. Here the challenges of cities against urban settlements were discussed. Subsequently, in 1996 in Istanbul, Turkey discussed the issue of sustainable cities and decent housing for all. Last October 20, 2016, the third conference was held in Quito, Ecuador where the theme was sustainable cities and human settlements for all. This last conference approved the New Urban Agenda, NAU. (UN 2016). In order to adopt the strategies suggested by the NAU, USL will developed a new module to impact in terms of disability around urban issues. Each USL project will contribute to form a large georeferenced database that will provide the opportunity to generate research that improves the quality of life of this sector of the population.

\section{CONCLUSION}

Until now, USL has proven that noise and security are two of the most important facts on the user perception and they are strongly related to vegetation. As seem on the interviews, people preferred spaces with vegetation, but just if there is a good care of them, otherwise this might appear unsecure. This is also proved by the light sensor. We can see that places with a good care of the vegetation have more people than those that have a lack of vegetation.

In addition, the web based platform has improved the scope of the projects. Different institutions have shown interest on the projects. Therefore, we are working with the mobility ministry of Puebla, Mexico to improve the sensors.

USL has been applied to analyze public urban spaces. However, in the further work section, we described very shortly how our approach could be used in commercial activities as well as for handicapped people. Most of the spaces are not designed to promote production, collaboration and meeting. We think that our approach can help the communication between artisans and other people. USL can contribute with specific recommendations for this kind of spaces and create insights, which will allow a better use and performance of these kind of urban spaces. The spaces can also promote meetings and increase the usage of urban facilities.

Our approach has been tested manually. We discovered in this process the steps to analyze urban spaces and multisensory data provided by sensors. This process will be automatized to analyze urban data. The web based platform that allowed us to do the manual analysis will now integrate the automated process.

Finally, USL can contribute to improve the quality of life of handicapped and elder people. Getting deeper into the user's perception and finding a way for measuring and comparing urban spaces, will give strong foundations for the development of cities. 


\section{ACKNOWLEDGEMENTS}

This research was supported by Instituto Tecnológico de Monterrey through the fund for experimentation in educational innovation NOVUS 2015. We thank our students Vicente San Emeterio Castillo, Gabriel Benavides Mariño and Ricardo Alfonso Ricardez Tinoco who provided insight and expertise that greatly assisted this research.

\section{REFERENCES}

Bosch (2015). Connected Devices and GmbH. Cross-Domain Development Kit XDK110.

Cowan \& Stewart (2007). Ecological Design. Island Press

Debord, G. (1958). Théorie de la dérive. París, Francia: Internationale Situationniste.

Degen, M. \& Gillian, M. (2012). The sensory experiencing of urban design: the role of walking and perceptual memory. Urban studies. The open university.

Design Thinking (2017). Design Thinking Español. http://designthinking.es/inicio/herramienta.php?id=58\&fase $=$ def ine (3rd June 2017)

Downs R. et al. (1978). Geography and the Mind: An Exploration of Perceptual Geography. American Behavioral Scientist, 22, pp 59-77.

Downs, R. \& Stea, D. (1973). Image and environment: cognitive mapping and spatial behavior. Chicago, Illinois: Aldain Publishing company.

Dschool. (2009). Bootcamp bootleg. Stanford: Hasso Plattner, Institute of Design at Stanford.

Gibson J. (1979) The ecological approach of visual perception. Psychology Press, New York and London.

Lynch, K. (1960). La imágen de la ciudad. Buenos Aires, Argentina: Infinito.

Marcel, A. J. (1983). Conscious and unconscious perception: An approach to the relations between phenomenal experience and perceptual processes. Cognitive psychology, 15(2).

Rapoport, Amos. (1978). Aspectos Humanos de la Forma Urbana. Hacia una Confrontación de las Ciencias Sociales con el Diseño de la Forma Urbana. Barcelona, Editorial Gustavo Gili.

UN (2016). Tercera Conferencia de Naciones Unidas sobre Vivienda y el Desarrollo Urbano Sostenible (HABITAT III). Declaración de Ecuador.

Usigli, T. C. (2016). Cómo 4 marcas de moda acercan el trabajo artesanal a los millennials.

Westerink J. et al (2008) Modelling the physics of storm surges. Physics Today. 